\title{
Variations in origin of the genitofemoral nerve from the lumbar plexuses in north Indian population(a cadaveric study)
}

\begin{abstract}
The genitofemoral is the nerve of genital region and cutaneous nerve to the femoral region. The origin of nerve is from lumbar plexus, having the root value from the ventral rami of L1 and L2. It supplies to the scrotum by its genital branch, which comes out through inguinal canal from the abdomen and its femoral branch supplies to the skin over the femoral region. It has less clinical significance even than the knowledge of genitofemoral nerve is important for surgeons who perform the surgery for repair of the inguinal hernia. The present study is conducted in the Department of Anatomy of Government Medical College Patiala(India) on 30 cadavers which are embalmed with $10 \%$ formalin and fixed. To expose the lumbar plexus opened the abdomen carefully. The roots of the lumbar plexus are cleared by sacrificing the psoas major muscle. The root values of the genitofemoral nerve are exposed by cleaning the roots and recorded the variations in its origin from the lumbar plexus and photographed. The aim of this study is to record the variations in origin of the genitofemoral nerve from the lumbar plexus and to compare the present study with the standard literature and studies done by other authors and to impart the knowledge of variations in origin of the genitofemoral nerve from the lumbar plexus. The present study is helpful for the surgeons who perform the surgery for the repair of inguinal hernia and lower abdominal surgery.
\end{abstract}

Volume I Issue 3 - 2015

\author{
Gurbachan Singh Gindha,' Deepti Arora,' \\ Subhash Kaushal, ${ }^{2}$ Usha Chhabra² \\ 'MM Medical College, Himachal Pradesh, India \\ ${ }^{2}$ Government Medical College, Punjab, India
}

Correspondence: Gurbachan Singh Gindha, MM Medical College, Himachal Pradesh, India, Email drgindhags@yahoo.com

Received: October 12, 2015 | Published: November 02, 2015

Keywords: psoas major muscle, lumbar plexus, root value, genital region, femoral region, inguinal ligament, inguinal hernia, scrotum, mons pubis, ureteric calculus, femoral artery, spermatic fascia, cremastic muscle

\section{Introduction}

The genitofemoral nerve originates from the lumbar plexus, having the root value L1 and L2 from ventral rami of spinal cord and is formed within the substance of psoas major muscle. Nerve descends obliquely forwards through the muscle, to emerge on its abdominal surface near the medial border, opposite to the $3^{\text {rd }}$ or $4^{\text {th }}$ lumbar vertebra. It then descends beneath the peritoneum on psoas major muscle, crosses obliquely behind the ureter and divides above the inguinal ligament into genital and femoral branches; it often divides close to its origin, in which case its branches emerge separately from psoas major muscle. The genital branch crosses the lower part of the external iliac artery and enters the inguinal canal by the deep ring and supplies the Cremastic muscle and the skin of the scrotum in males. In female, it accompanies the round ligament and ends in the skin of the mons pubis and labium majus. The femoral branch descends lateral to the external iliac artery and sends a few filaments round it before crossing the deep circumflex iliac artery, passing behind the inguinal ligament and entering the femoral sheath lateral to the femoral artery. It pierces the anterior layer of the femoral sheath and fascia lata and supply to the skin anterior to the upper part of the femoral triangle. It connects with the femoral intermediate cutaneous nerve and supplies the femoral artery. Like the ilioinguinal nerve, the genital branch may be injured during inguinal surgery. The ureteric pain due to ureteric calculus refers to the cutaneous area involved from spinal segments which supply the ureter, mainly T11 and T12, and shoots down and forwards from the loin to the groin and scrotum or labium majus; it may extend into the proximal anterior aspect of the thigh by projection to the genitofemoral nerve (L1 and L2). The cremaster muscle, which has the same innervation, may reflexly retract the testis. ${ }^{1,2}$ The lumbar plexus of nerves is formed anterior to the lumbar transverse processes, within the proximal attachment of psoas major muscle. The nerve network is composed of the anterior rami of L1 to L4 nerves. The genitofemoral nerve with root value of L1 and L2 is the branch of the lumbar plexus. ${ }^{3}$

The femoral branch of the genitofemoral nerve supplies the area of skin below the middle of inguinal ligament. The genital branch supplies that part of the abdominal wall herniated into the scrotum for the descent of the testis(i.e. the spermatic cord). It is sensory to the tunica vaginalis and the spermatic fasciae, and motor to the Cremastic muscle. It supplies small area of anterior scrotal region in males and labial skin in females. ${ }^{4}$ The chronic pain may occur in the inguinal region after the repair of the inguinal hernia by the surgeon. This problem was first named by Heise and Starling 5 as "mesh inguinodynia" in 1998..$^{5}$ The incidence of chronic pain after inguinal hernial repair has been reported by Poobalan et al. ${ }^{6}$ to be as high as $54 \%$. Recently, Aroori and Spence ${ }^{7}$ suggested that this issue should be involved in the informed consent forms of all patients undergoing any type of hernia repair. The most common reported cause of entrapment of the genitofemoral relates to surgical trauma. ${ }^{8,9}$ Other rare case reports include wearing tight clothing and direct trauma to the groin resulting in local scarring. ${ }^{10,11}$ Guerin et al. ${ }^{12}$ done the dissection for 60 lumbar plexus on the cadavers and studied the variations in branches from the lumbar plexus. They divided the intervertebral disc spaces from L1 and L2 to L4 and L5 into four zones. Zone-1, is at the level of L2 and L3, it contained the sympathetic only. Zone-2, was having the genitofemoral nerve. Zone-3, is the safe working zone. Zone- 
4 , in this zone all other branches of lumbar plexus are lying. Gu et al. ${ }^{13}$ determined with cadaveric study, they a safe working zone for performing lateral interbody fusion. This area was located between the anterior border of the lumbar nerve and the posterior border of the sympathetic trunk. The location of the genitofemoral nerve was responsible for a narrowing of the safe zone at L2 and L3 level. McCrory and Bell ${ }^{14}$ described that the genitofemoral nerve arises from the rami of the L1 and L2 spinal nerve roots and passes through the psoas major muscle, emerging on its anterior aspect. The nerve divides into the genital and femoral branches. The genital branch enters the inguinal canal and then shares in sensory supply of the scrotal skin or the mons pubis and labium majus. The femoral branch passes under the inguinal ligament to supply a small patch of skin on the anterior thigh.

\section{Materials and methods}

The present study will be conducted in the Anatomy Department of Government Medical College Patiala, Punjab, India. The dissection will be done on 30 human cadavers which are embalmed with $10 \%$ formalin and fixed. 30 embalmed cadavers for 60 lumbar plexuses are the material for the study. The dissection will be done according to the Cunningham's Manual of Practical Anatomy. ${ }^{15}$ The abdomen will be opened and the psoas major muscle will be exposed on both the sides of lumbar vertebrae. The roots of lumbar plexuses will be exposed and cleaned. The formation of the genitofemoral nerve will be exposed and root value of this nerve will be noted and recorded by sacrificing the psoas major muscle. The formation and course of the genitofemoral nerve from the lumbar plexus will be traced and recorded. Any variation in origin of the genitofemoral nerve and its distribution will be noted and photographed. The present study will be compared with the standard literature and studies done by other authors.

\section{Observations}

The present study was concluded on 30(22 male cadavers and 8 female cadavers Table 1) human cadavers which were embalmed with $10 \%$ formalin and fixed. 60 (30 of right side +30 of left side) lumbar plexus were exposed. Out of 60 specimens, 44 specimens were of male sex and 16 specimens were of female sex. The root value of the genitofemoral nerve was exposed on both the sides. The variations found in origin of the genitofemoral nerve from the lumbar plexuses are given in Table 2. Two female cases of the genitofemoral nerve (1 case of right side and another 1 case of left side) i.e.(3.33\%) of cases were arising from the root value of T12 and L1. These were present in two different female cases and were unilaterally present. No such variation was found in males (Photograph 1) (Figure 1). 1 case $(1.67 \%)$ of cases in male on left side was having the root value of L1. It was a unilateral case. No such variation was found in female. L1 and L2 is the normal root value of the genitofemoral nerve. $35(58.33 \%)$ cases out of 60 cases were having the root value of L1 and L2. While $34(56.67 \%)$ cases in males out of 60 total cases were bilaterally in origin, while 1 case $(1.67 \%)$ of cases was unilaterally arising from L1 and L2 on right side and on left side the nerve was arising from L1 only. In females 3 cases $(5.00 \%)$ on right side and 3 cases $(5.00 \%)$ on left side were arising from the root value of L1 and L2. These cases were bilaterally present (Photograph 2) (Figure 2). L1, L2 and L3 root value of the genitofemoral nerve was found in 3 male cases. 2 cases $(3.33 \%)$ were bilateral in origin while 1 case $(1.67 \%)$ male was unilateral in origin on left side. No such variation was found in females (Photograph 3) (Figure 3).

Table I Distribution of specimens according to sex

\begin{tabular}{lll}
\hline Sex and no. of cadavers & No. of specimens (Right+Left) & Percentage \\
\hline Male $=22$ & 44 & 73.33 \\
Female $=8$ & 16 & 26.67
\end{tabular}

Table 2 Variations found in root value in origin of the genitofemoral nerve

\begin{tabular}{|c|c|c|c|c|c|c|c|c|}
\hline \multirow{2}{*}{ Root value } & \multicolumn{4}{|l|}{ Male cases } & \multicolumn{4}{|c|}{ Female cases } \\
\hline & Right side & $\%$ age & Left side & $\%$ age & Right side & $\%$ age & Left side & $\%$ age \\
\hline TI2, LI & - & - & - & - & 1 & 1.67 & 1 & 1.67 \\
\hline LI & - & - & I & 1.67 & - & - & - & - \\
\hline LI, L2 & 18 & 30 & 17 & 28.33 & 3 & 5 & 3 & 5 \\
\hline LI, L2, L3 & I & 1.67 & 2 & 3.33 & - & - & - & - \\
\hline L2 & 2 & 3.33 & 2 & 3.33 & - & - & - & - \\
\hline L2, L3 & I & 1.67 & - & - & I & 1.67 & - & - \\
\hline Not found & - & - & - & - & 3 & 5 & 4 & 6.67 \\
\hline
\end{tabular}




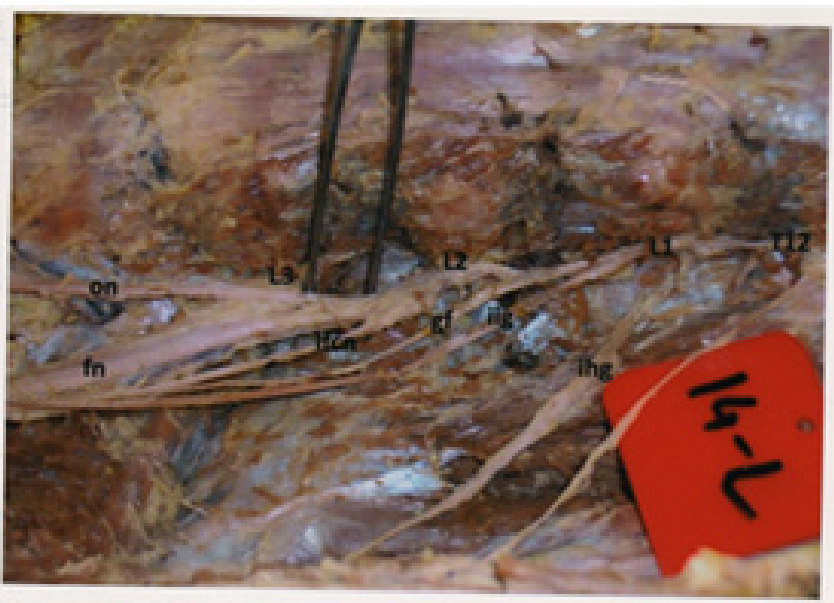

Photograph-1

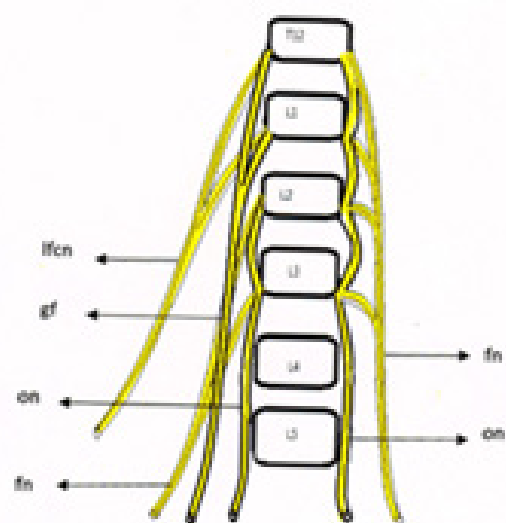

Figure-I

Figure I Showing the origin of genitofemoral nerve (GF) from TI2, LI on right and nerve is not present on the left side.
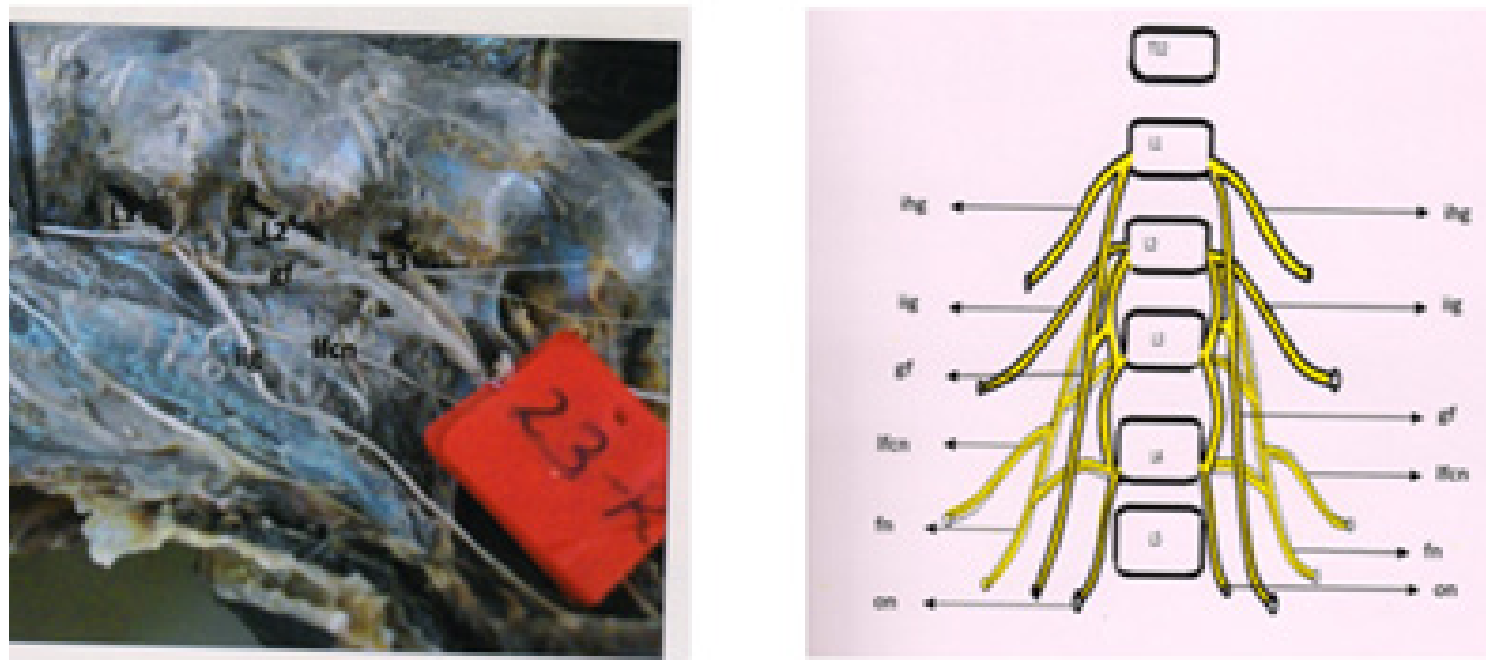

Figure 2 Showing the origin of genitofemoral nerve (GF) from LI, L2 on both sides.
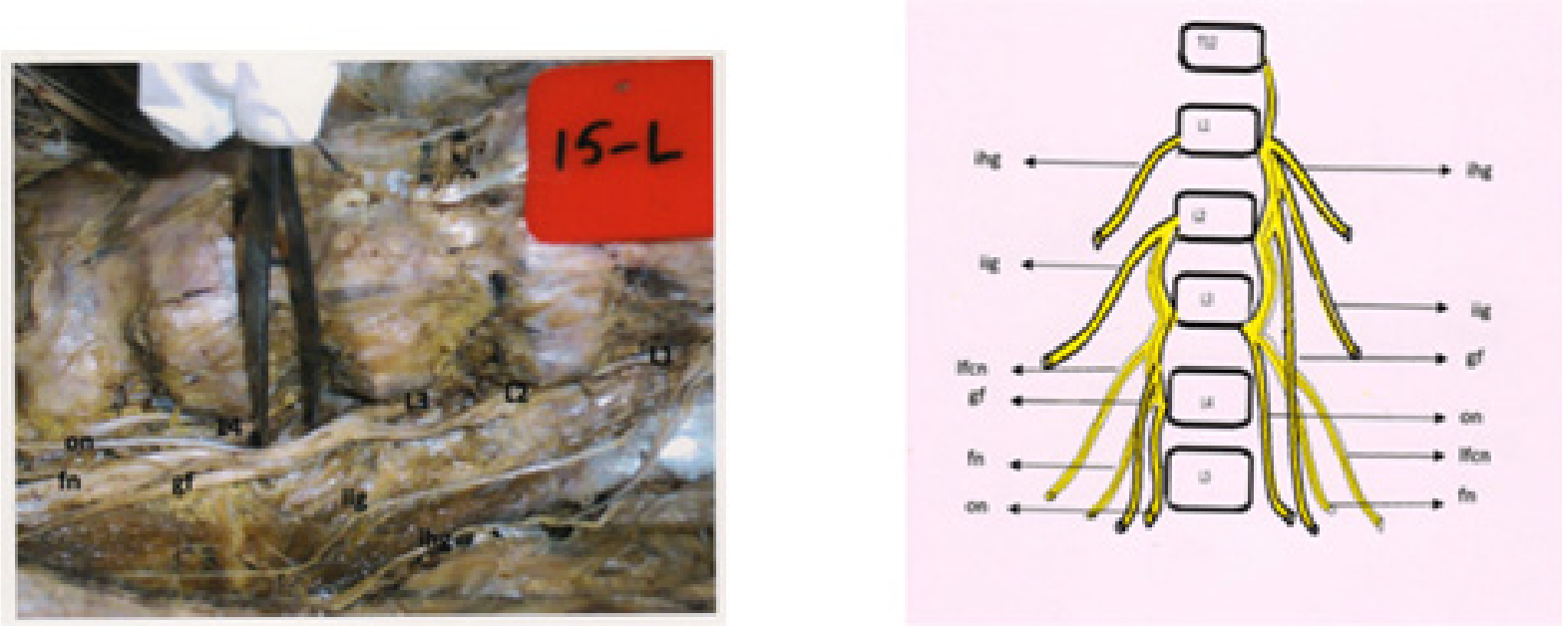

Photograph-III

Figure- III

Figure 3 Showing origin of genitofemoral nerve (GF) on right side from L2, $L 3$ and on left side from LI, L2, and L3.

Citation: Gindha GS, Arora D, Kaushal, et al.Variations in origin of the genitofemoral nerve from the lumbar plexuses in north Indian population(a cadaveric study). MOJ Anat Physiol. 20I5; I(3):72-76. DOI: 10.15406/mojap.2015.01.000I5 
4 cases $(2$ cases $3.33 \%$ on right side, and 2 cases $3.33 \%$ on left side) in males were arising from the root value of L2 only. These were bilateral in origin. No such variation was found in females. 1 case $(1.67 \%)$ in males on right side, 1 case $(1.67 \%)$ in females on right side were arising from the root value of L2 and L3. Both the cases were unilateral in origin, and arising on the right side only (Photograph 4)
(Figure 4). In 7 cases of females no origin of the genitofemoral nerve was found. In 6 cases $(10.00 \%)$ it was found bilaterally absent and 1 case $(1.67 \%)$ was absent on left side while on the right side of same case was giving the origin to the genitofemoral nerve from the root value of T12 and L1 which is also abnormal origin of the nerve which is described above.

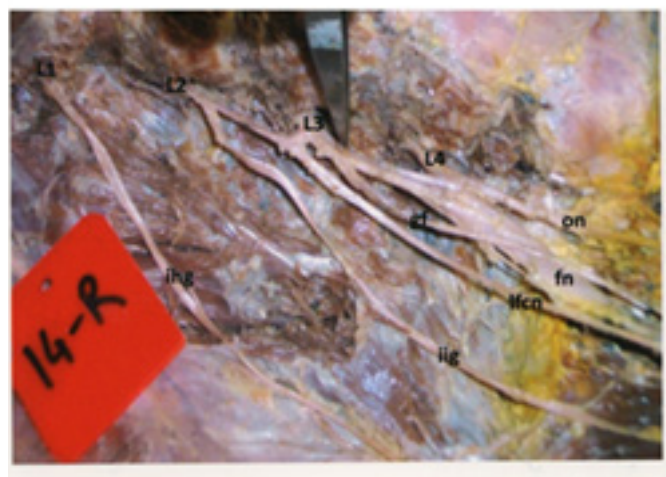

Photograph-IV

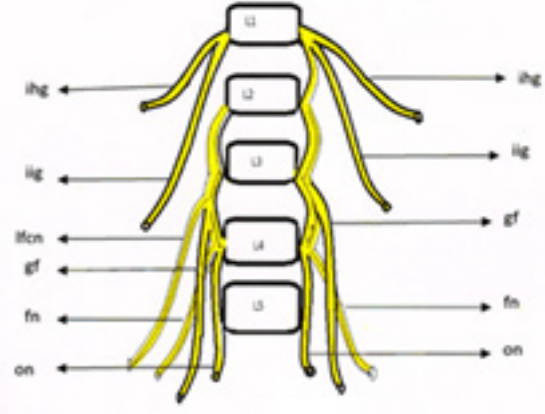

Figure-IV

Figure 4 Showing the origin of genitofemoral nerve (GF) from L2 and L3 on both sides.

\section{Discussion}

Bergman et al. ${ }^{16}$ the genitofemoral nerve is considered by some authors as the most variable nerve of the lumbar plexus. The genital and the femoral branches of the nerve may arise as separate offshoots of the lumbar plexus. Either of them may be derived from the first or second lumbar nerves and occasionally from the third. The genital branch sometimes receives fibers from the 12th thoracic nerve. In a study of the genitofemoral nerve in 200 bodies(400) nerves. $80.0 \%$ presented as a single trunk and $19.75 \%$ as two rami: genital and femoral. The genitofemoral nerve was present in all cases. In their study they have shown that $75 \%$ nerves were arising from the root value of L1 and L2. 5\% from L2, $0.25 \%$ from L2 and L3. Matthias et al. ${ }^{17}$ Stated that the genitofemoral nerve pierced the psoas major muscle as a single root and after $7 \pm 3.5 \mathrm{~cm}$ it divided into the genital and femoral rami in $(58 \%)$ of the cases while in the rest(42\%) it was divided into two rami within the psoas major muscle and never united again. Anloague and Huijbregts ${ }^{18}$ used the dissection of 34 lumbar plexuses to look at the prevalence of anatomical variations in the lumbar plexus. The most common variation occurred in 9 of 34 plexuses $(26.5 \%)$ and included a split of genitofemoral nerve into genital and femoral branches within the substance of the psoas major muscle with fibers of the psoas major muscle passing between these branches. 7 variant the genitofemoral nerve $(20.6 \%)$ had this bifurcation occur at the upper than mid-portion of the anterior surface of psoas major muscle.

Bergman et al. ${ }^{19}$ stated that the genitofemoral nerve arises as a single root in $80 \%$ and as a double root in $20 \%$, of the cases. He also claimed that these roots may originate from L1 and L2, or L2 and L3. As compared to the present study he did not find the origin of this nerve from T12. Deniz et al. ${ }^{20}$ found that the genitofemoral nerve was originating from the ventral ramus of L2 on right side of a 35years old female cadaver. In present study we found 4 male cases bilaterally present arising from the root value of L2. In the present study the variations found in origin of the genitofemoral nerve from the 60 lumbar plexuses are as from T12 and L1 in 2 cases $(3.33 \%)$ of 2 female gender, from L1 in 1 case $(1.67 \%)$ in male gender, from L1 and L2 in
41 cases $(68.33 \%)$ both in males and females, from L1, L2 and L3 in 3 cases $(5 \%)$ all the 3 male cases, from L2 in 4 cases( $6.67 \%)$ all the 4 cases are male cases, from L2 and L 3 in 2 cases(3.33\%) one male case of right side and one female case of right side, and the nerve was not found in 7 cases $(11.67 \%$ ) all the seven cases were female cases and no such case was found in males.

\section{Conclusion}

The present study was conducted on 30 human cadavers(60 lumbar plexuses) to find out the variations in origin of the genitofemoral nerve. Various variations in origin of the genitofemoral nerve from the lumbar plexuses were noted. The normal root value of the genitofemoral nerve is L1 and L2, but the nerve was having the variations in its origin from root values like, T12 and L1, L1 only, L1, L2 and L3, L2 only, L2 and L3, and in some cases origin of the genitofemoral nerve was not found. These variations are having clinical significance. The genitofemoral nerve may be injured during the surgical procedures, particularly in lower abdominal region surgery and surgery for the repair of the inguinal hernia. The injury to the genitofemoral nerve can affect the temperature regulation of testis. Thus, a better knowledge of the regional anatomy and its variations is essential for preventing from the lesions of the genitofemoral nerve and its branches.

\section{Acknowledgements}

None.

\section{Conflict of interest}

Author declares that there is no conflict of interest.

\section{References}

1. Stanring S. Gray's Anatomy: The Anatomical Basis of Clinical Practice. Chapter posterior abdominal wall, lumbar plexus. 40th ed. London: Churchill Livingstone Elsevier; 2011. p. 1978-1080.

2. Snell RS. Snell's Clinical Anatomy by Regions. 9th ed. Chapter abdomen. New Delhi: Wolters Kluwer/Lippincott Williams and Wilkins Pvt. Ltd; 2012. 222p. 
3. Moore KL. Moore clinical oriented Anatomy. 7th ed. Chapter abdomen. New Delhi, New York, London, Hong Kong, Sydney and Tokyo: Wolters Kluwer/Lippincott Williams Wilkins; 2010. 313p.

4. Sinnatamby CS. Last Anatomy Regional and applied. 12th ed. chapter abdomen. Edinburg, London, New York, Oxford, Philedelphia, St. Louis, Sydney, Toronto: Churchill Livingstone Elsevier; 2011. p. 325-326.

5. Heise CP, Starling JR. Mesh inguinodynia: anew clinical syndrome after inguinal herniorrhaphy. J Am Coll Surg. 1998;187(5):514-518.

6. Poobalan AS, Bruce J, Smith WC, et al. A review of chronic pain after inguinal herniorrhaphy. Clin J Pain. 2003;19(1):48-54.

7. Aroori S, Spence RA. Chronic pain after hernia surgery - an informed consent issue. Ulster Med J. 2007;76(3):136-140.

8. Starling, J, Harms BA. Diagnosis and treatment of genitofemoral and ilioinguinal neuralgia. World J Surg. 1989;13(5):586-591.

9. Laha R, Rao S, Pidgeon CN, et al. Genitofemoral neuralgia. Surg Neurol. 1977;8(4):280-282.

10. McGee RK. Genitofemoral causalgia (A new syndrome). Can Med Assoc J. 1942;46(4):326-329.

11. O’Brien M. Genitofemoral neuropathy. BMJ. 1989;1:1052.

12. Guerin P, Obeid I, Gille O, et al. The lumbosacral plexus: anatomic considerations for minimally invasive retroperitoneal transpsoas approach. Surg Radiol Anat. 2011;34(2):151-157.
13. Gu Y, Ebraheim NA, Xu R, et al. Anatomic considerations of the posterolatral lumbar disk region. Orthopedic. 2001;24(1):56-58.

14. McCrory P, Bell S. Nerve entrapment Syndromes as a Cause of Pain in the Hip, Groin and Buttock. Sports Med. 1999;27(4):261-274.

15. Romanes GJ. Cunningham's Manual of Practical Anatomy, posterior abdominal wall, lumbar plexus. 5th ed. New York: Oxford University Press; 2013;2:182-186.

16. Bergman RA, Afifi AK, Miyauchi R. External structure of genitofemoral nerve in post fetal life in man Folia Morphol. Warsaw; 1975;34:425-435.

17. Rab M, Ebmer J, Delon AL. Anatomical variability of the ilioinguinal nerve and genitofemoral nerve: implications for treatment of groin pain. Plast Reconstr Surg. 2001;108(6):1618-1623.

18. Anloague P, Huijbregts P. Anatomical Variations of the Lumbar Plexus: A Descritive Anatomy Study with Proposed Clinical Implications. $J$ Man Manip Ther. 2009;17(4):107-114.

19. Bergman RA, Afifi AK, Miyauchi R. Variations in formation of ilioinguinal nerve. 2006.

20. Deniz U, Mustafa A, Alev K. Multiple variations of the nerves arising from the lumbar plexus. Neuroanatomy. 2006;5:37-39. 